\title{
Effects of $\operatorname{rod} A$ and $p b p 2 b$ Disruption on Cell Morphology and Oxidative Stress Response of Streptococcus thermophilus CNRZ368
}

\author{
Annabelle Thibessard, Annabelle Fernandez, Brigitte Gintz, Nathalie Leblond-Bourget,* \\ and Bernard Decaris
}

\author{
Laboratoire de Génétique et Microbiologie, UMR INRA 1128, IFR 110, Faculté des Sciences \\ de l'Université Henri Poincaré Nancy 1, 54506 Vandoeuvre-lès-Nancy, France
}

Received 12 October 2001/Accepted 5 February 2002

\begin{abstract}
Insertional mutagenesis was used to isolate clones from Streptococcus thermophilus CNRZ368 that were modified in their abilities to tolerate oxidative stress. During this process, two menadione-sensitive clones (6G4 and 18C3) were found to display abnormal cell morphologies and distorted chain topologies and were further studied. Molecular characterization of both $6 \mathrm{G} 4$ and $18 \mathrm{C} 3$ mutants indicated that they were disrupted in open reading frames homologous to $\operatorname{rod} A$ and $p b p 2 b$, respectively. Both genes encoded proteins in Escherichia coli that were described as being implicated in peptidoglycan synthesis during the process of cell elongation and to function in determining the rod shape of the cell. This work reports a possible connection between peptidoglycan biosynthesis and oxidative stress defense in $S$. thermophilus CNRZ368.
\end{abstract}

Streptococcus thermophilus is a lactic acid bacterium (LAB) used as a starter of fermentation for the conversion of milk into yogurt and many cheeses (e.g., Emmental, Gruyère, mozzarella, and cheddar). It is an anaerobic aerotolerant microorganism that grows as linear chains of ovoid cells.

The growth of rod-shaped bacteria and some coccal bacteria occurs by successive cycles of elongation and division $(13,20)$. During elongation, the sacculus is extended due to the insertion of disaccharide pentapeptide units into the existing peptidoglycan with the aid of penicillin-binding proteins (PBPs) (for recent reviews, see references 3, 6, 8, and 19). When the cell mass doubles, division is initiated at a lateral position by the formation of a septal wall from which the two new cell poles will be divided (for reviews, see references 4 and 18). In rod-shaped bacteria, these alternating processes, i.e., elongation and septation, are viewed as competing systems and each requires the presence of specific proteins $(4,16,22)$. For instance, PBP3 and FtsW carry out septation $(2,9,11,16)$, while PBP2 and RodA act specifically in the elongation step (7, 17, $22,24)$ and are needed to maintain the rod-like morphology of the cell. More precisely, PBP2 has transpeptidase activity in Escherichia coli and requires an active RodA protein to be fully functional (10).

The peptidoglycan is considered to assume two main functions: it is responsible for maintaining the shape of the cell (for a review, see reference 21), and it provides protection to the protoplast from external and internal osmotic forces. However, its role is not strictly limited to these activities. In LAB, resistance to stresses (such as UV radiation and acidic $\mathrm{pH}$ ) depends on genes involved in peptidoglycan and teichoic acid synthesis (for a review on $\mathrm{LAB}$, see reference 3 ).

Our initial goal was to identify genes implicated in the oxidative stress defense of $S$. thermophilus CNRZ368. To this end,

\footnotetext{
* Corresponding author. Mailing address: Laboratoire de Génétique et Microbiologie, UMR INRA 1128, IFR 110, UHP, Faculté des Sciences, 54506 Vandoeuvre-lès-Nancy. Phone: (33) 3839120 54. Fax: (33) 383912500 . E-mail: bourget@nancy.inra.fr.
}

insertional mutagenesis with pGh9:ISS1, a plasmid developed by Maguin et al. (14), was used. The resulting mutants were selected for their modified responses to menadione (an $\mathrm{O}_{2}{ }^{--}$generating compound) (A. Thibessard, unpublished data). In this paper, we report the physiological and molecular characterization of two clones (6G4 and 18C3) that were not only sensitive to menadione but were also found to have altered morphologies and reduced growth rates.

Identification of disrupted loci in $6 \mathrm{G} 4$ and $18 \mathrm{C3}$ genomes. Southern blot hybridization with pGh9:ISS1 as a probe indicated that integration of pGh9:ISS1 occurred in a single locus of the $18 \mathrm{C} 3$ genome and in a single locus of the $6 \mathrm{G} 4$ genome (data not shown). The disrupted loci were identified by cloning and sequencing the regions flanking the transposed structure. For the mutant $18 \mathrm{C} 3$, one of the two fragments $\left(18 \mathrm{C} 3-\mathrm{I}^{\mathrm{R}}\right)$ was cloned. DNA sequence data obtained from $483 \mathrm{bp}$ of this fragment revealed that it contained the partial sequences of two putative open reading frames (ORFs) (Fig. 1A). The disrupted ORF showed $98 \%$ identity to the $p b p 2 b$ gene, and the second ORF was homologous to recM (100\% identity); both genes were from $S$. thermophilus Sfi6 (23). Since the complete sequences of both genes have already been obtained in an $S$. thermophilus strain, the sequencing of the whole $p b p 2 b$ gene in CNRZ368 was not completed.

Additionally, the two fragments flanking the pGh9:ISS1 insertion locus in the mutant 6G4 were cloned, and a total sequence of $1,855 \mathrm{bp}$ was determined (Fig. 1B). Sequence analysis revealed that the ORF, into which pGh9:ISS1 integrated, encoded a predicted protein of 416 amino acids. A search of GenBank for homologous proteins showed that this protein was $61 \%$ identical (79\% similarity) to RodA (a putative rod-shaped determining protein) of Streptococcus pneumoniae, and it was therefore designated RodA.

Transcriptional analysis of the 6G4 and $18 \mathrm{C} 3$ mutants. The $p b p 2 b$ gene has been shown to be monocistronic (23). To investigate the transcriptional organization of $\operatorname{rod} A$, total RNAs extracted from late-exponential-phase cells of $S$. thermophilus CNRZ368 were probed with digoxigenin-labeled 
A

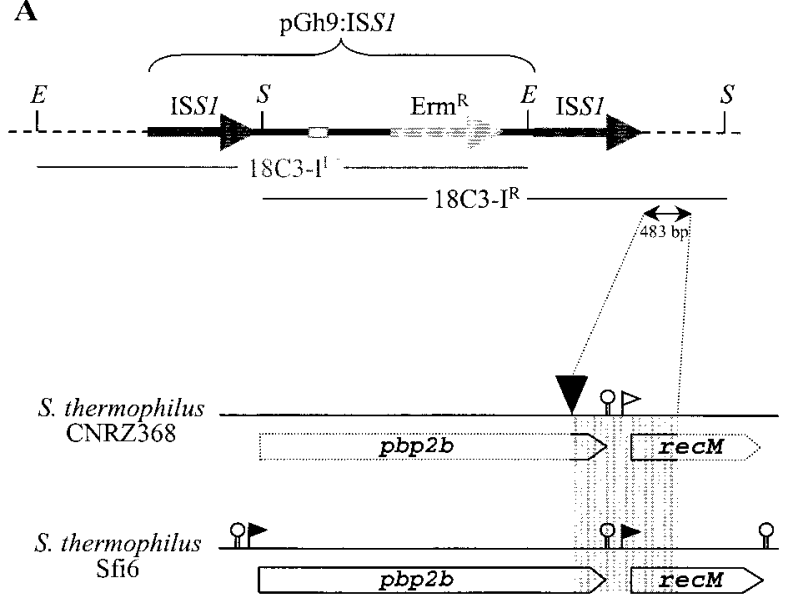

B

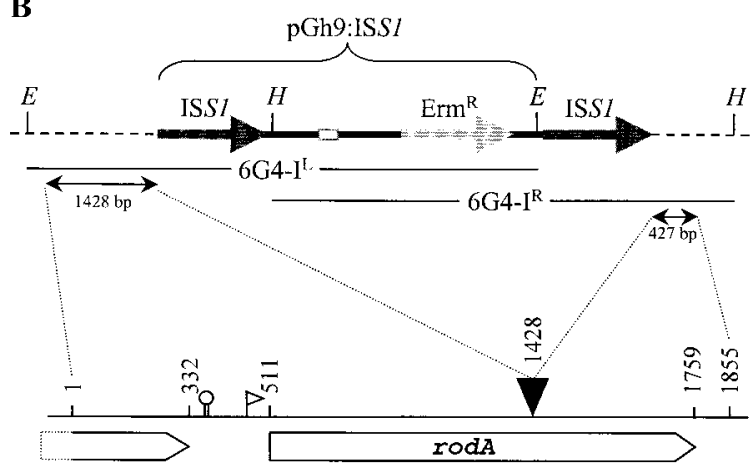

FIG. 1. Physical map of the chromosomal insertion sites of pGh9:ISS1. (A) Characterization of 18C3. The map of the pbp2b locus of Sfi6 was obtained from Stingele and Mollet (23). (B) Characterization of 6G4.The horizontal dashed lines represent the S. thermophilus genomic DNA. The large grey and black arrows represent the $\mathrm{Erm}^{\mathrm{r}}$ gene and ISS1 elements of the plasmid, respectively. The thermosensitive replication origin of the plasmid is represented by small grey rectangles. Restriction sites: E, EcoRI; H, HindIII; and S, SalI. X-I $\mathrm{I}^{\mathrm{L}}$ and X-I ${ }^{\mathrm{R}}$ (with X being the mutant name) indicate replicative molecules carrying the left and right junctions, respectively. The downward-pointing arrowheads indicate the site of pGh9:ISS1 insertion on the genome of $S$. thermophilus CNRZ368. The ORFs are indicated as open arrows. The filled flags indicate experimentally determined promoters (23), and the open flags indicate the putative promoters. The promoter of $\operatorname{rod} A$ is composed of a -35 sequence separated by 14 nucleotides from the extended -10 sequence. Putative rho-independent terminators are represented as hairpin loops.

transcripts complementary to an internal portion of $\operatorname{rodA}$ mRNA (Fig. 2A). Northern hydridization revealed a single transcript of approximately 1,450 bases, which is consistent with the idea that $\operatorname{rod} A$ is a monocistronic unit (Fig. 2B).

To determine if $\operatorname{rod} A$ and $p b p 2 b$ were constitutively transcribed, the levels of expression of both genes were examined by real-time reverse transcription-PCR (iCycler; Bio-Rad) with RNA samples isolated from exponential-phase (optical density at $\left.600 \mathrm{~nm}\left[\mathrm{OD}_{600}\right]=0.55\right)$ and early-stationary-phase $\left(\mathrm{OD}_{600}\right.$ $=1.6$ ) cultures of $S$. thermophilus CNRZ368. The amount of cDNA for each gene was normalized to the quantity of $h s t H$ cDNA present in each RNA preparation, which previously has been shown to be expressed at a constant rate (data not shown). The $\operatorname{rod} A$ and $p b p 2 b$ transcripts appeared to be equally abundant in both growth phases (data not shown) and to be constitutively expressed.

Growth and morphological characteristics of the $6 \mathrm{G} 4$ and $18 \mathrm{C} 3$ mutants. Mutations of $\operatorname{rod} A$ or $p b p 2 b$ were accompanied by a reduction of the growth rate. Thus, in terms of growth parameters, $S$. thermophilus CNRZ368 exhibited a lag phase, doubling time, and maximal $\mathrm{OD}_{600}$ of $1.5 \mathrm{~h}, 30 \mathrm{~min}$, and 2.0, respectively, whereas both $6 \mathrm{G} 4$ and $18 \mathrm{C} 3$ mutants exhibited values of $1.7 \mathrm{~h}, 60 \mathrm{~min}$, and 1.6, respectively. These results suggest that RodA and PBP2b are involved in cell growth.

To determine whether impairment of RodA or PBP2b had an impact on the cell morphology of $S$. thermophilus, we examined the $6 \mathrm{G} 4$ and $18 \mathrm{C} 3$ mutants by light and scanning electron microscopies and compared them with the wild-type strain. For all examinations, samples were collected from stationary-phase cultures grown in liquid TPPY medium. The results of the examinations indicated that cells of both $6 \mathrm{G} 4$ and $18 \mathrm{C} 3$ mutants were spherical instead of ovoid (Fig. 3A). This was associated in both cases with a significant reduction of the cell size: the mean sizes were $2.3 \pm 0.5,2.0 \pm 0.6$, and $4.3 \pm 1$
$\mathbf{A}$

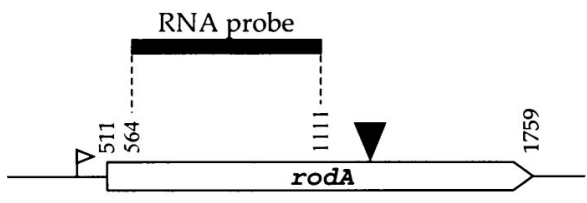

B

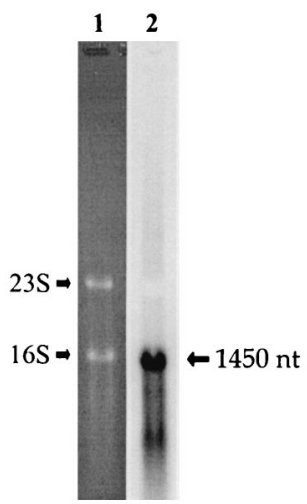

FIG. 2. Northern analysis of rodA from S. thermophilus CNRZ368. (A) Schematic showing the location of the $\operatorname{rod} A$ RNA probe utilized in the Northern experiment. The downward-pointing arrowhead indicates the site of pGh9:ISS1 insertion, and the open flag indicates the putative promoter. (B) Northern blot analysis of orf1 transcript. Lane 1, Results of ethidium bromide staining of RNA $(30 \mu \mathrm{g})$ from $S$. thermophilus CNRZ368 after agarose gel electrophoresis into a formaldehyde-denaturing $(0.8 \%)$ agarose gel. RNAs were extracted from late-exponential-phase $\left(\mathrm{OD}_{600}\right.$ of 1.4) culture in TPPY medium. $16 \mathrm{~S}$ and $23 \mathrm{~S}$ indicate the migrating positions of $16 \mathrm{~S}$ and $23 \mathrm{~S}$ rRNA, respectively. Lane 2, Result of the hybridization with the $\operatorname{rod} A$ probe. nt, nucleotides. 
A
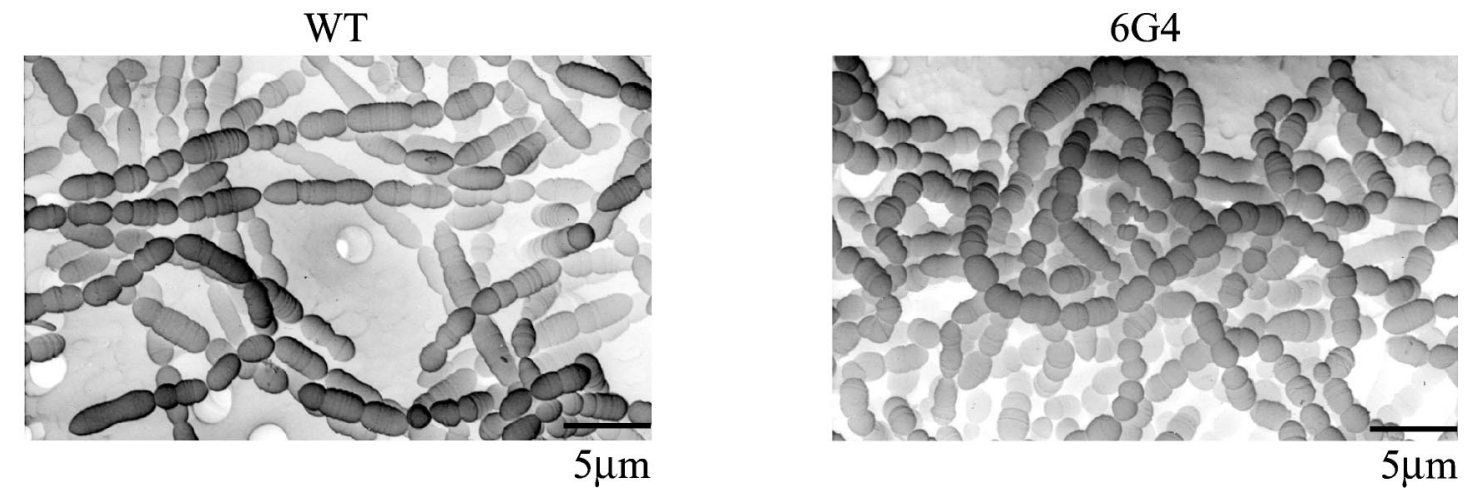

B

WT
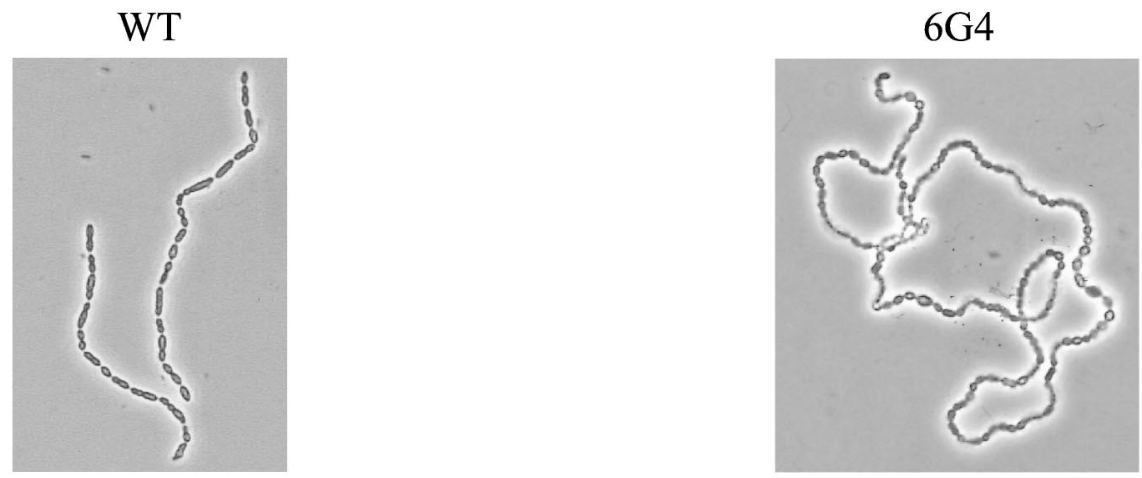

C

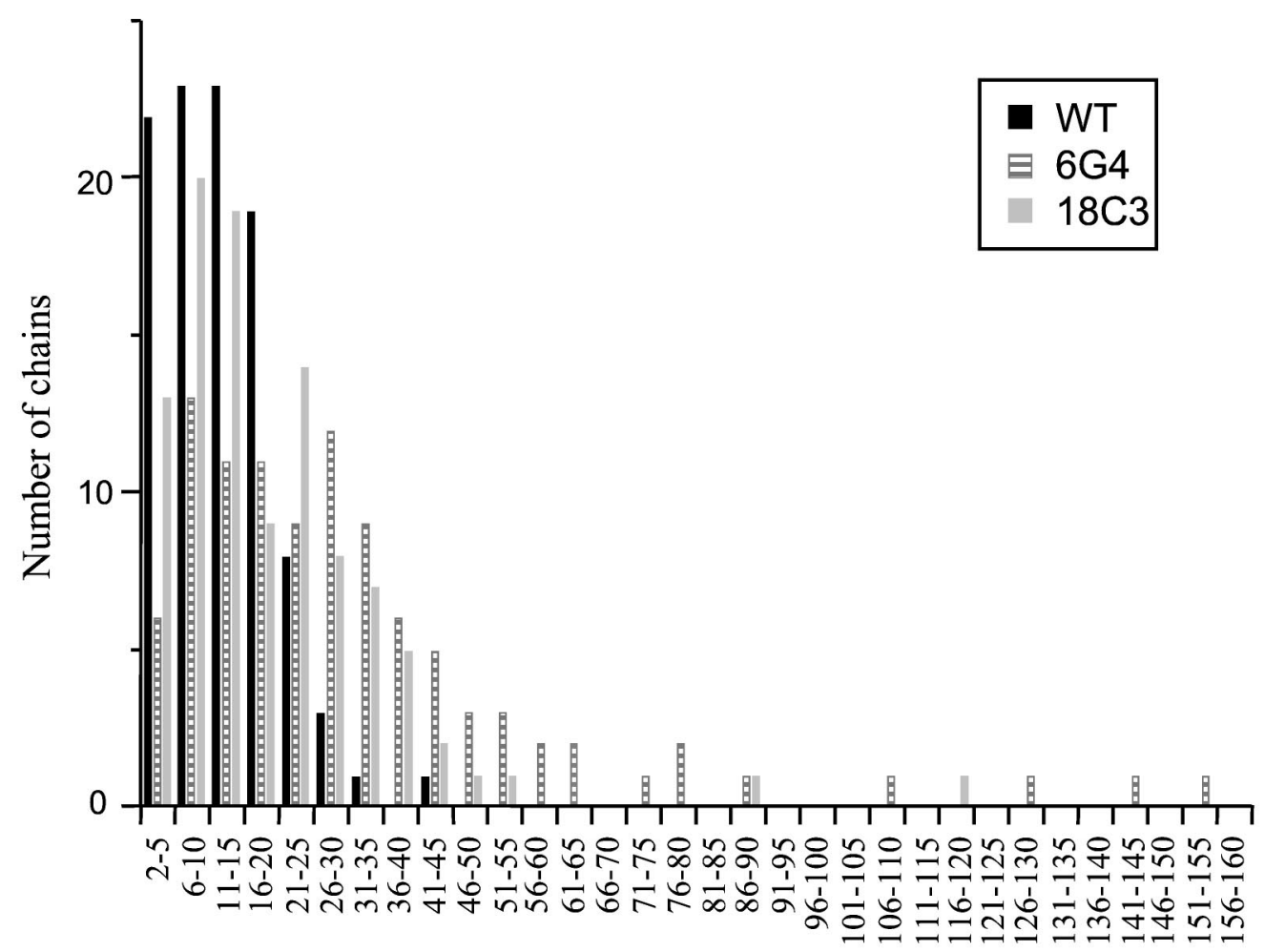

Number of cells per chain

FIG. 3. Morphological characterization of S. thermophilus CNRZ368 cells and chains. (A) Scanning electron micrographs of the wild-type (WT) and 6G4 strains. (B) Micrographs of the wild-type and 6G4 strains. Microscopy was performed with a Nikon D1 microscope. Magnification, $\times 1,000$. (C) Influence of $\operatorname{rod} A$ or $p b p 2 b$ disruption on chain length. 
$\mathbf{A}$

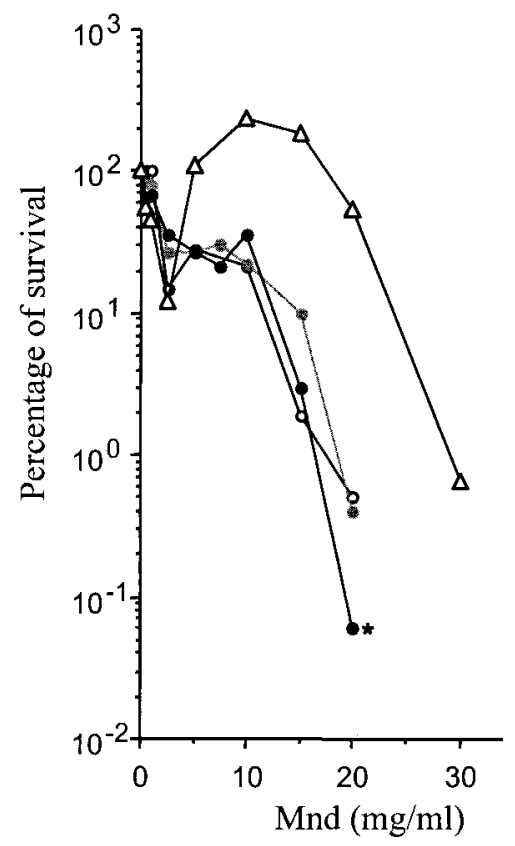

B

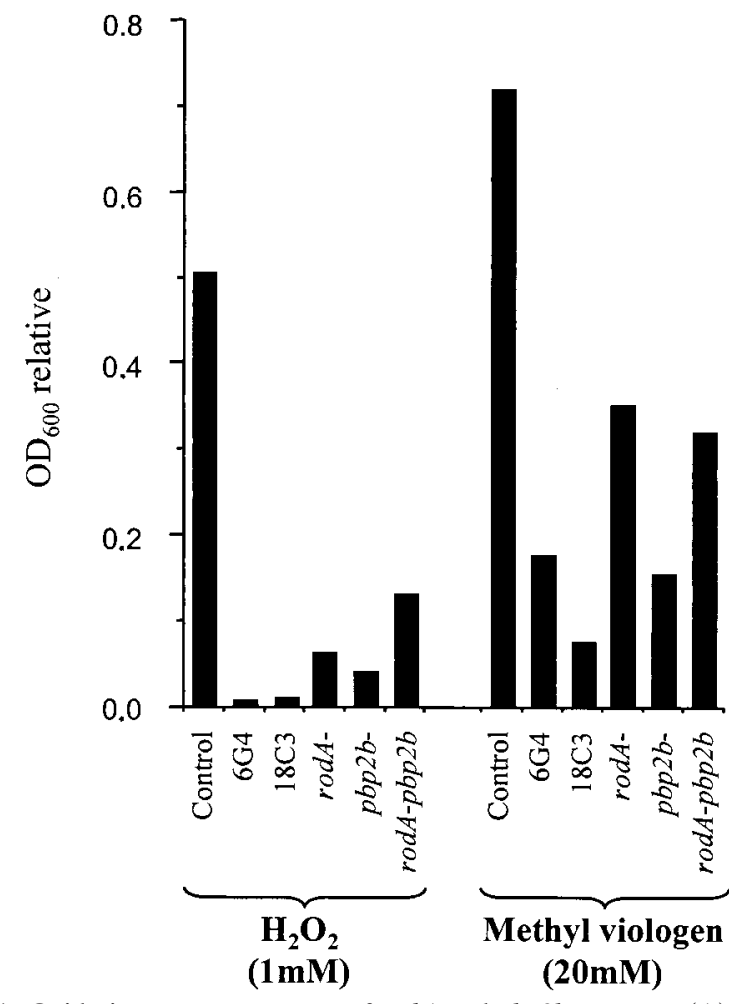

FIG. 4. Oxidative stress responses of $\operatorname{rod} A$ and $p b p 2 b$ mutants. (A) Survival rates in the presence of increasing concentrations of menadione (Mnd). Symbols: $\triangle$, control; $\bigcirc, 6 \mathrm{G} 4 ; \bigcirc, 18 \mathrm{C} 3$; and $\bigcirc$ (marked with an asterisk), $\operatorname{rod} A-p b p 2$. The control experiments were done with the strain 2C3, which was derived from CNRZ368 by pGh9:ISS1 transposition and which was neither affected in its oxidative stress response nor in its cell morphology. Cells were grown overnight in milk medium diluted 100-fold into fresh TPPY medium. At an $\mathrm{OD}_{600}$ of 0.6 , the culture was split and samples were treated with menadione for $3 \mathrm{~h}$. Cells were then plated on TPPY liquid medium and incubated for $20 \mathrm{~h}$ in jars. The percentage of surviving cells was determined by comparing $\mu \mathrm{m}$ for the $18 \mathrm{C} 3,6 \mathrm{G} 4$, and wild-type cells, respectively. Moreover, cells of the $6 \mathrm{G} 4$ and $18 \mathrm{C} 3$ mutants were arranged in chains that were not linear, like those of the wild-type strain, but curled (Fig. 3B); the 18C3 cells were also twisted. Finally, the number of cells per chain was significantly higher in the mutants than in the wild-type strain, as indicated in the graph in Fig. 3C.

Taken together, these results indicate that both RodA and $\mathrm{PBP} 2 \mathrm{~b}$ play a fundamental role in the maintenance of cell shape in $S$. thermophilus, a function that is therefore not restricted to rod-shaped bacteria like E. coli or Bacillus subtilis. Our findings on the phenotypes associated with $\operatorname{rod} A$ and $p b p 2 b$ mutations support the idea that RodA and PBP2b are key proteins of the elongation system of $S$. thermophilus as well as those of $E$. coli and B. subtilis, homologues of the $S$. thermophilus system. Moreover, our data suggest that elongation is not required for cell division.

Additionally, a mutation in either $\operatorname{rod} A$ or $p b p 2 b$ was associated with an increase in the number of cells per chain, suggesting that RodA and PBP2b may also play a role in cell segregation within chains.

Rod $A$ and $p b p 2 b$ mutations are not lethal in S. thermophilus CNRZ368. In S. thermophilus CNRZ368, disruption of either $\operatorname{rod} A$ or $p b p 2 b$ was not lethal, which contrasts with what occurs in $E$. coli. In order to examine the effects of simultaneous rodA and $p b p 2 b$ gene disruptions on viability and on cell phenotype, a double mutant was constructed. To do this, the $18 \mathrm{C} 3 \Delta \mathrm{pGh}$ strain was obtained by plasmid excision produced by homologous recombination between the two copies of ISS1. This strain was erythromycin sensitive and yet it was disrupted for $p b p 2 b$, since one copy of the ISS1 element was kept in the original target site. This strain was then transformed with the plasmid pGh9 carrying a 548-bp fragment containing an internal sequence of the $\operatorname{rod} A$ gene. A $\operatorname{rod} A \operatorname{pbp} 2 b$ double mutant, resulting from plasmid integration in the chromosomal copy of $\operatorname{rod} A$ via a single-crossover event, was selected and confirmed by Southern blotting (data not shown). This $\operatorname{rod} A$ pbp $2 b$ double mutant was viable and displayed no significant phenotypic difference compared to the single $p b p 2 b$ mutant from which it was derived. This result reinforces the idea that both proteins are implicated in the same peptidoglycan biosynthesis process. Moreover, both $\operatorname{rod} A$ and $p b p 2 b$ genes were dispensable for the growth of $6 \mathrm{G} 4$ and $18 \mathrm{C} 3$ mutants, suggesting that, contrary to what occurs in $B$. subtilis, the division machinery is not influenced by the impairment of the elongation system in $S$. thermophilus CNRZ368 (9).

Both $\operatorname{rod} A$ and $p b p 2 b$ take part in $S$. thermophilus defense against oxidative stress. (i) Construction of truncated $\operatorname{rod} A$

the number of $\mathrm{CFU}$ in treated samples with the number in untreated samples. All experiments were performed in triplicate. The results of typical experiments are presented here. (B) Growth inhibition of various mutants on TPPY medium in the presence of $\mathrm{H}_{2} \mathrm{O}_{2}$ and methyl viologen. The concentrations of the oxidative agents used in this experiment were $1 \mathrm{mM}$ for $\mathrm{H}_{2} \mathrm{O}_{2}$ and $20 \mathrm{mM}$ for methyl viologen (paraquat). The inhibition of growth was measured by determining the ratio of the $\mathrm{OD}_{600}$ after a 20 -h incubation in the presence of oxidizing agent to the $\mathrm{OD}_{600}$ in the absence of treatment. All experiments were performed in triplicate. The data from typical experiments are displayed here. 
and $p b p 2 b$ mutants. To determine whether the menadione sensitivity of $6 \mathrm{G} 4$ and $18 \mathrm{C} 3$ was the result of the insertion of pGh9:ISS1 rather than the result of a secondary mutation, a single mutant of each gene was reconstructed. To do this, two recombinant plasmids were constructed. In the first, a 548-bp fragment containing an internal sequence of $\operatorname{rod} A$ (from codon 18 to codon 200) was inserted in pGh9. The second construct carried a 1,140-bp DNA fragment containing an internal sequence of $p b p 2 b$ (from codon 190 to codon 569). Both plasmids were introduced separately into the wild-type strain via electroporation (15). Transformants were selected at $30^{\circ} \mathrm{C}$ on M17 plates containing erythromycin $(5 \mu \mathrm{g} / \mathrm{ml})$. Mutants derived from plasmid integration via a single-crossover event were obtained with both plasmids and verified by Southern blot analysis (data not shown). The strains resulting from $\operatorname{rod} A$ or $p b p 2 b$ truncation were termed $\operatorname{rod} A(\mathrm{t})$ and $p b p 2 b(\mathrm{t})$, respectively.

(ii) Sensitivity of $\operatorname{rod} A$ and/or $p b p 2 b$ mutants to hydrogen peroxide and superoxide-generating agents. Several assays were developed to assess the tolerances of the $6 \mathrm{G} 4,18 \mathrm{C} 3, \operatorname{rod} A(\mathrm{t})$, $p b p 2 b(\mathrm{t})$, and $\operatorname{rod} A-p b p 2 b$ mutants to oxidizing agents. To test menadione tolerance, cells were grown in TPPY medium until the $\mathrm{OD}_{600}$ was 0.6. Then, the culture was split and samples were treated for $3 \mathrm{~h}$ with various concentrations of menadione, and the cells were further plated on solid TPPY medium to count the surviving CFU. The survival of the 6G4 and $18 \mathrm{C} 3$ mutants in the presence of menadione confirmed the increased susceptibilities of the mutants compared to that of the control (Fig. 4A). Similar results have been obtained for $\operatorname{rod} A(\mathrm{t})$ and $p b p 2 b(\mathrm{t})$ (data not shown), indicating that both RodA and PBP2b proteins play a role in the oxidative stress response of $S$. thermophilus CNRZ368. Moreover, no drastic difference was observed between the results obtained for all of these single mutants and that for the $\operatorname{rod} A p b p 2 b$ double mutant, indicating that $\operatorname{rod} A$ and $p b p 2 b$ disruptions did not produce a cumulative effect different from those produced by single mutations. Thus, the 6G4 and 18C3 mutants seem to be altered in the same mechanism of defense against oxidative stress.

In order to determine whether this sensitivity was menadione specific, the effects of other oxidizing agents were checked by use of a protocol inspired by King et al. (12). Briefly, the $\mathrm{OD}_{600}$ was used to estimate the cellular concentration of each sample after a 20-h incubation in the presence of $\mathrm{H}_{2} \mathrm{O}_{2}$ or methyl viologen $\left(\mathrm{O}_{2}{ }^{-}-\right.$-generating molecule $)$. As shown in Fig. $4 \mathrm{~B}$, all mutants showed reduced abilities to develop compared to the control regardless of which oxidizing molecule was added to the medium. Thus, RodA and PBP $2 \mathrm{~b}$ have a role in the defense against hydrogen peroxide and superoxide radicals.

Conclusion. Altogether, our results clearly show that RodA and PBP2b are not only implicated in peptidoglycan biosynthesis but also involved in the oxidative stress response. There are a few hypotheses that may explain the increased sensitivities of the $\operatorname{rod} A$ and $p b p 2 b$ mutants to oxidative agents. One hypothesis is based on the major function assigned to the cell wall, that is, the maintenance of cell integrity. In the literature, the importance of the cellular envelope for cell survival under environmental stresses has already been reported. In LAB, improper biosynthesis of this barrier has been reported to induce an increased sensitivity to either UV treatment (5) or acid stress (1). Thus, disruption of $\operatorname{rod} A$ or $p b p 2 b$ may cause a modification of the architecture of the peptidoglycan, reducing the ability of the cell to protect against attack. Mutations in $\operatorname{rod} A$ or $p b p 2 b$ may reduce the number of cross-links between glycan chains, lessen the degree of elongation of the chains, or prevent damage to the peptidoglycan from being repaired.

An alternative hypothesis is to view PBP2b and RodA as part of a chain of interacting elements that can induce a protective system defending the cell against environmental stresses. The lack of one or the other protein would then result in the breakage of such a signaling pathway and lead to the loss of oxidative stress resistance.

Whatever the hypothesis considered, RodA and PBP2b are likely to belong to the same network since the double $\operatorname{rod} A$ $p b p 2 b$ mutant does not show any increased sensitivity compared to the single $\operatorname{rod} A$ and $p b p 2 b$ mutants.

Nucleotide sequence accession number. The nucleotide sequences reported have been deposited in the GenBank database under accession no. AF399833 and AF399832.

We thank E. Maguin for providing us the pGh9:ISS1 plasmid, Mark Wilks for his advice about the English formulation of the manuscript, and Luc Marchal for help with the scanning electron microscopy.

This work was supported by Le ministère de la recherche et de la Technologie.

\section{REFERENCES}

1. Boyd, D. A., D. G. Cvitkovitch, A. S. Bleiweis, M. Y. Kiriukhin, D. V. Debabov, F. C. Neuhaus, and I. R. Hamilton. 2000. Defects in D-alanyllipoteichoic acid synthesis in Streptococcus mutans results in acid sensitivity. J. Bacteriol. 182:6055-6065.

2. Boyle, D. S., M. M. Khattar, S. G. Addinall, J. Lutkenhaus, and W. D. Donachie. 1997. ftsW is an essential cell-division gene in Escherichia coli. Mol. Microbiol. 24:1263-1273.

3. Delcour, J., T. Ferain, M. Deghorain, E. Palumbo, and P. Hols. 1999. The biosynthesis and functionality of the cell-wall of lactic acid bacteria. Antonie Leeuwenhoek 76:159-184

4. Donachie, W. D. 1993. The cell cycle of Escherichia coli. Annu. Rev. Microbiol. 47:199-230.

5. Duwat, P., A. Cochu, S. D. Ehrlich, and A. Gruss. 1997. Characterization of Lactococcus lactis UV-sensitive mutants obtained by ISS1 transposition. J. Bacteriol. 179:4473-4479.

6. Goffin, C., and J. M. Ghuysen. 1998. Multimodular penicillin-binding proteins: an enigmatic family of orthologs and paralogs. Microbiol. Mol. Biol. Rev. 62:1079-1093.

7. Henriques, A. O., P. Glaser, P. J. Piggot, and C. P. Moran, Jr. 1998. Control of the cell shape and elongation by the $\operatorname{rodA}$ gene in Bacillus subtilis. Mol. Microbiol. 28:235-247.

8. Holtje, J. V. 1998. Growth of the stress-bearing and shape-maintaining murein sacculus of Escherichia coli. Microbiol. Mol. Biol. Rev. 62:181203.

9. Ishino, F., H. K. Jung, M. Ikeda, M. Doi, M. Wachi, and M. Matsuhashi. 1989. New mutations fts-36, fts-33, and fts $W$ clustered in the mra region of Escherichia coli chromosome induce thermosensitive cell growth and division. J. Bacteriol. 171:5523-5530.

10. Ishino, F., W. Park, S. Tomioka, S. Tamaki, I. Takase, K. Kunugita, H. Matsuzawa, S. Asoh, T. Ohta, and B. G. Spratt. 1986. Peptidoglycan synthetic activities in membranes of Escherichia coli caused by over production of penicillin-binding protein 2 and RodA protein. J. Biol. Chem. 261:70247031.

11. Khattar, M. M., K. J. Begg, and W. D. Donachie. 1994. Identification of FtsW and characterization of a new fts $W$ division mutant of Escherichia coli. J. Bacteriol. 176:7140-7147.

12. King, K. Y., J. A. Horenstein, and M. G. Caparon. 2000. Aerotolerance and peroxide resistance in peroxidase and perR mutants of Streptococcus pyogenes. J. Bacteriol. 182:5290-5299.

13. Lleo, M. M., P. Canepari, and G. Satta. 1990. Bacterial shape regulation: testing of additional predictions unique to the two-competing-sites model for peptidoglycan assembly and isolation of conditional rod-shaped mutants from some wild-type cocci. J. Bacteriol. 172:3758-3771.

14. Maguin, E., H. Prévost, S. D. Ehrlich, and A. Gruss. 1996. Efficient insertional mutagenesis in lactococci and other gram-positive bacteria. J. Bacteriol. 178:931-935.

15. Marciset, O., and B. Mollet. 1994. Multifactorial experimental designs for 
optimizing transformation: electroporation of Streptococcus thermophilus. Biotechnol. Bioeng. 43:490-496.

16. Matsuhashi, M., M. Wachi, and F. Ishino. 1990. Machinery for cell growth and division: penicillin-binding proteins and the other proteins. Res. Microbiol. 141:89-103.

17. Matsuzawa, H., S. Asoh, K. Kunai, K. Muraiso, A. Takasuga, and T. Ohta 1989. Nucleotide sequence of the $\operatorname{rod} A$ gene, responsible for the rod shape of Escherichia coli: $\operatorname{rod} A$ and the $p b p A$ gene, encoding penicillin-binding protein 2, constitute the $\operatorname{rod} A$ operon. J. Bacteriol. 171:558-560.

18. Nanninga, N. 1991. Cell division and peptidoglycan assembly in Escherichia coli. Mol. Microbiol. 5:791-795.

19. Nanninga, N. 1998. Morphogenesis of Escherichia coli. Microbiol. Mol. Biol. Rev. 62:110-129.

20. Satta, G., R. Fontana, P. Canepari, and G. Botta. 1979. Peptidoglycan synthesis in cocci and rods of a pH-dependent, morphologically conditional mutant of Klebsiella pneumoniae. J. Bacteriol. 137:727-734.

21. Shockman, G. D., and J. F. Barret. 1983. Structure, function, and assembly of cell walls of gram-positive bacteria. Annu. Rev. Microbiol. 37:501-527.

22. Spratt, B. G. 1975. Distinct penicillin-binding proteins involved in the division, elongation and shape of Escherichia coli K12. Proc. Natl. Acad. Sci. USA 72:2999-3003.

23. Stingele, F., and B. Mollet. 1996. Disruption of the gene encoding penicillinbinding protein $2 \mathrm{~b}(p b p 2 b)$ causes altered cell morphology and cease in exopolysaccharide production in Streptococcus thermophilus Sfi6. Mol. Microbiol. 22:357-366.

24. Tamaki, S., H. Matsuzawa, and M. Matsuhashi. 1980. Cluster of $m r d A$ and $\operatorname{mrdB}$ genes responsible for the rod shape and mecillinam sensitivity of Escherichia coli. J. Bacteriol. 141:52-57. 